\title{
Stimuli-Responsive Guest Binding and Releasing by Dendritic Polymer-Based Hydrogels
}

\author{
By Yasumasa KANEKIYO, ${ }^{1,2,3 *}$ Hiroaki TAO, ${ }^{2}$ and Börje SELLERGREN ${ }^{3}$
}

Newly designed hydrogels that show stimuli-responsive molecular recognition have been created. Hyperbranched polyethyleneimine (PEI) was modified with methacryl groups and then copolymerized with acrylamide. The resultant copolymer can reversibly bind guest molecules in methanol-water mixed solvent through the interaction between PEI and guest molecules. When the methanol content in the solvent was raised to shrink the polyacrylamide chains, the bound guest molecules were physically entrapped within the hydrogel matrix. These results show that the polyacrylamide chains act as a physical barrier surrounding PEI that can reversibly be opened and closed in response to solvent composition.

KEY WORDS: Host-guest System / Hyperbranched / Dendrimers / Stimuli-sensitive Polymers /

Dendrimers are highly branched macromolecules with welldefined nanostructures. Because of their distinctive properties, they have found use in a wide range of applications. ${ }^{1-4}$ One unique feature of dendrimers is the existence of cavities inside which various kind of guest molecules are accommodated. ${ }^{5-13}$ According to the concept of "dendritic box" that was proposed by Meijer et al., ${ }^{14-17}$ guest molecules can be physically trapped inside a dendrimer by constructing a "shell" onto the dendrimer surface. When the shell is chemically cleaved, the trapped guest molecules are released from the dendritic box. ${ }^{17}$ This unique concept would provided a new strategy for applications such as drug delivery systems and sensing devices. It should be noted, however, that the dendritic box requires harsh conditions for the chemical cleavage of the shell and the cleaving process is irreversible. These facts may limit the practical use of the dendritic boxes. It is, therefore, desired to realize reversible opening and closure of the shell under mild conditions.

Another problem in dendrimer system is that dendrimer synthesis is time-consuming and costly by which practical large-scale applications are limitted. To overcome the problem, hyperbranched (dendritic) polymers that are prepared in onestep reactions of $\mathrm{AB}_{\mathrm{m}}$ monomers ${ }^{18-22}$ have been introduced as alternative building blocks for practically usable materials. Although the chemical structures are not as well defined as in the case of dendrimers, hyperbranched polymers are known to have dendrimer-like properties such as the ability to encapsulate guest molecules. ${ }^{23-27}$ Among them, polyethyleneimine (PEI) has been extensively studied. PEI is prepared by a ringopening polymerization of ethyleneimine and is obtained on a large scale with relatively low polydispersity. It is randomly branched but still has a fairly defined structure. In recent years, PEI has been shown to be useful for many practical applications. ${ }^{28-31}$ In this paper, we describe a novel methodology for the construction of PEI-based materials having stimuli-responsive guest binding and releasing ability.

\section{EXPERIMENTAL}

\section{Materials}

Polyethyleneimine $\left(\mathrm{PEI}, M_{\mathrm{n}}=25000, M_{\mathrm{w}} / M_{\mathrm{n}}=2.5\right.$, degree of branching of 65-75\%) was supplied by Prof. Rainer Haag. Glycidyl methacrylate (GM) was purchased from Fluka. Acrylamide (AAm) and potassium persulfate were purchased from Kanto chemicals. 1-Pyrenecarboxylic acid (PMC), 2naphthalenecarboxylic acid (NMC) and 2,6-naphthalenedicarboxylic acid (NDC) were purchased from Aldrich. 1-Pyrenemethanol (Py-OH) was purchased from Tokyo chemical industry. All the materials were used as received.

\section{Preparation of Copolymers}

$43 \mathrm{mg}$ of PEI (containing $1 \mathrm{mmol}$ of amino groups) was reacted with $57 \mathrm{mg}$ of GM $(0.4 \mathrm{mmol})$ in $1 \mathrm{~mL}$ of DMSO at $60^{\circ} \mathrm{C}$ for $12 \mathrm{~h}$. A TLC measurement showed that GM was quantitatively reacted with amino groups in PEI since the spot corresponding to GM disappeared. Subsequently, water (and DMSO) $)^{32}$ and AAm were added to the solution (for amounts see Table I). To this solution was added $5 \mathrm{mg}$ of potassium persulfate to initiate a polymerization. After standing the solution at $25^{\circ} \mathrm{C}$ for $24 \mathrm{~h}$, a transparent gel-like copolymer was obtained. For purification, the copolymer was immersed in a

Table I. Composition of copolymers

\begin{tabular}{cccccc}
\hline Copolymer & PEI & GM & AAm & Yield & $\begin{array}{c}\text { PEl:AAm } \\
\text { in copolymer }\end{array}$ \\
\hline A & $\begin{array}{c}43 \mathrm{mg} \\
(1 \mathrm{mmol})^{\mathrm{b}}\end{array}$ & $\begin{array}{c}57 \mathrm{mg} \\
(0.4 \mathrm{mmol})\end{array}$ & $\begin{array}{c}1500 \mathrm{mg} \\
(21.1 \mathrm{mmol})\end{array}$ & $85.0 \%$ & $1: 19.4$ \\
\hline B & $\begin{array}{c}43 \mathrm{mg} \\
(1 \mathrm{mmol})^{\mathrm{b}}\end{array}$ & $\begin{array}{c}57 \mathrm{mg} \\
(0.4 \mathrm{mmol})\end{array}$ & $\begin{array}{c}250 \mathrm{mg} \\
(3.5 \mathrm{mmol})\end{array}$ & $77.1 \%$ & $1: 1.72$ \\
\hline
\end{tabular}

aMole ratio between amine unit of PEI and AAm unit in copolymers determined by elemental analysis ( $\mathrm{C} / \mathrm{N}$ ratio). ${ }^{\mathrm{b}}$ Mole number of amine unit.

\footnotetext{
${ }^{1}$ INFU, University of Dortmund, Otto Hahn Str. 6, 44221 Dortmund, Germany

${ }^{2}$ National Institute of Advanced Industrial Science and Technology (AIST), 16-1 Onogawa, Tsukuba 305-8569, Japan

${ }^{3}$ Kitami Institute of Technology, 165 Koen-cho, Kitami 090-8507, Japan

*To whom correspondence should be addressed (Tel: +81-157-26-9389, Fax: +81-157-24-7719, E-mail: kanekiyo@mail.kitami-it.ac.jp).
} 
large volume of water and then methanol while occasionally replacing the solvents. Finally, the copolymer was dried under vacuum.

\section{Measurement of Guest Binding}

Copolymer A (ca. $13 \mathrm{mg})$ or copolymer B (ca. $2 \mathrm{mg}$ ) was immersed in $9.9 \mathrm{~mL}$ of methanol/water mixed solvent for $12 \mathrm{~h}$ to reach the swelling equilibria. To the solution was added $0.1 \mathrm{~mL}$ of methanol solution containing a guest molecule $(10 \mathrm{mM})$ and then stirred for $12 \mathrm{~h}$. The amount of bound guest molecule was quantified by measuring a fluorescence spectrum of a 100 times-diluted supernatant solution upon excitation at $340 \mathrm{~nm}$. All the experiments were conducted at $25^{\circ} \mathrm{C}$.

\section{Measurement of Swelling Ratio}

Each gel were taken out of solutions and weighed after wiping excess water from the gel surface.

\section{Instrument}

Fluorescence spectra were recorded on Hitachi F-4500 fluorescence spectrophotometer.

\section{RESULTS AND DISCUSSION}

The outline of our strategy is shown in Figure 1. PEI was modified with a polymerizable group, and then copolymerized with acrylamide. We synthesized two kinds of copolymers changing the acrylamide content as shown in Table I. The materials thus obtained can be regarded as nanocomposites consisting of PEI moieties interconnected by polyacrylamide chains. It is known that PEI contains primary, secondary, and tertiary amines. Glycidyl methacrylate (GM) reacts with both primary and secondary amines to form secondary and tertiary amines, respectively. Thus, total amino group contents in the synthesized copolymers were calculated as follows; copolymer A: $0.68 \mathrm{mmol} \mathrm{g}^{-1}$, copolymer B: $4.48 \mathrm{mmol} \mathrm{g}^{-1}$.

The host-guest characteristics of the copolymers were investigated by measuring binding abilities toward PMC (1pyrenecarboxylic acid) in methanol-water mixed solvents (results are shown in Figure 3). For structure of guest molecules, see Figure 2. It is clearly seen from Figure 3(a) that the binding ability of copolymer $\mathbf{A}$ (closed squares) is greatly dependent on the solvent composition. We supposed that the observed solvent dependency is caused by changes in the swelling state of the copolymer gel. Thus, the swellingshrinking behaviors were quantified by measuring the weight changes of the copolymer hydrogels before and after immers-

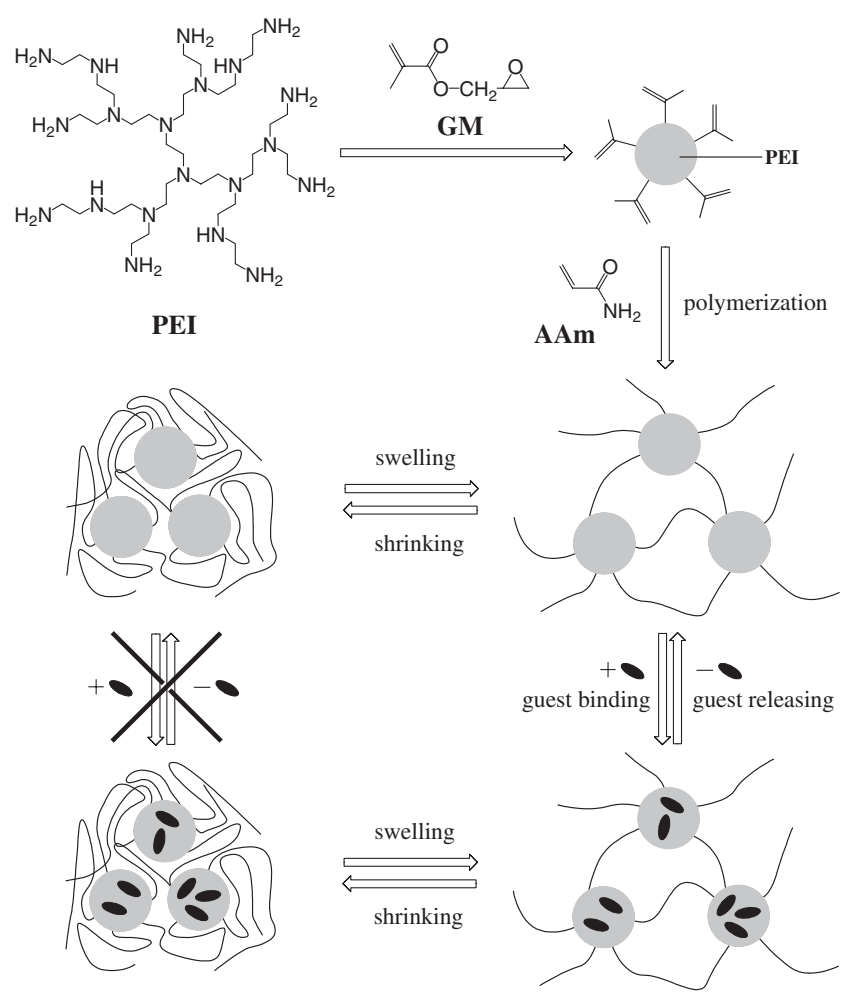

Figure 1. Stimuli-responsive guest binding and releasing.

ing in mixed solvents. Shown in Figure 4 are plots of swelling ratios of the gels defined by equation (1):

$$
\text { Swelling ratio }=\left(W_{\text {wet }}-W_{\text {dry }}\right) / W_{\text {dry }}
$$

Where $W_{\text {wet }}$ and $W_{\text {dry }}$ are the weight of swollen and dry copolymers, respectively. Since polyacrylamide is soluble in water but insoluble in methanol, the copolymer gel should be changed from swollen to shrunken state with increasing methanol content. Contribution from PEI portion on the swelling ratio should be negligible because the PEI contents in the copolymers are small ( $c a .2 .9$ wt. \% for copolymer $\mathbf{A}$ and ca. 19.3 wt. \% for copolymer B).

In order to clarify the driving force for the guest binding, $\mathrm{HCl}$ or $\mathrm{NaOH}$ was added to the solution. In the presence of $1 \mathrm{mM} \mathrm{HCl}$ where amino groups in PEI should be fully protonated, ${ }^{5-9}$ the copolymer almost lost its binding ability toward PMC (Figure 3(a), open squares). The binding toward PMC was also suppressed in the presence of $1 \mathrm{mM} \mathrm{NaOH}$ (data not shown). These facts indicate that the binding is mainly driven by the electrostatic interaction between an amino group

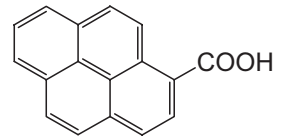

PMC<smiles>O=C(O)c1ccc2ccccc2c1</smiles>

NMC<smiles>O=C(O)c1ccc2cc(C(=O)O)ccc2c1</smiles>

NDC

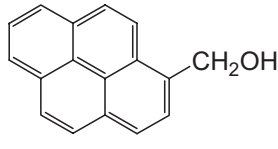

Py-OH

Figure 2. Chemical structure of guest molecules. 

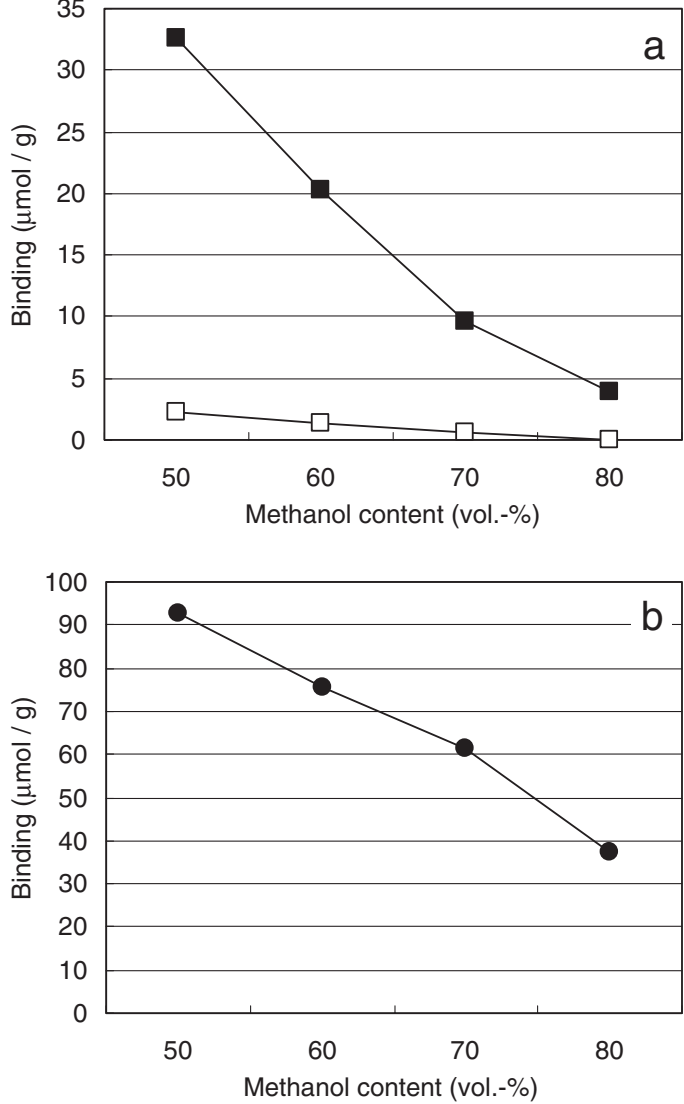

Figure 3. Binding capabilities of copolymers toward PMC in methanol-water mixed solvents in the absence $(\square, 0)$ and presence $(\square)$ of $1 \mathrm{mM}$ $\mathrm{HCl}$ : a) copolymer $\mathbf{A}, \mathbf{b})$ copolymer $\mathbf{B}$.

in PEI moiety and the carboxyl group in PMC. When the methanol content was $50 \%$, the amount of bound PMC was $32.6 \mu \mathrm{mol} \mathrm{g}^{-1}$. This means that $4.8 \%$ of the total amino groups were used for the binding of PMC. The PMC binding would be increased if more concentrated PMC solution is used. ${ }^{33}$ The importance of the amine-carboxylic acid interaction was additionally supported by examining binding affinity against other guest molecules. Table II shows that a dicarboxylic acid (NDC) have higher binding affinity than those for monocarboxylic acids (PMC and NMC), while $\mathrm{Py}-\mathrm{OH}$ having no carboxyl group has only small binding affinity. Dicarboxylic acids can interact with the copolymer by two-point aminecarboxylic acid interactions so that the equilibrium binding constants should be higher than those for monocarboxylic acids. Also, it is understandable the guest molecules not having carboxyl group lack driving force for the binding. We thus believe that the following mechanism is working on the stimulus-responsive ${ }^{34}$ guest binding: when the polyacrylamide chains are swollen, PMC molecule can freely diffuse within the polyacrylamide chains to reach the binding site (PEI moiety), whereas shrinkage of the polyacrylamide chains make the diffusion difficult so that PMC is prevented from reaching the binding site. In other words, the shrunken polyacrylamide chains can be regarded as a barrier through which diffusion of
Table II. Comparison of binding affinities of copolymer $\mathbf{A}$ toward guest molecules (methanol content: 50 vol.-\%)

\begin{tabular}{ccccc}
\hline Guest & PMC & NMC & NDC & Py-OH \\
\hline Binding $/ \mu \mathrm{mol} \mathrm{g}^{-1}$ & 32.6 & 28.9 & 44.7 & 3.8 \\
\hline
\end{tabular}

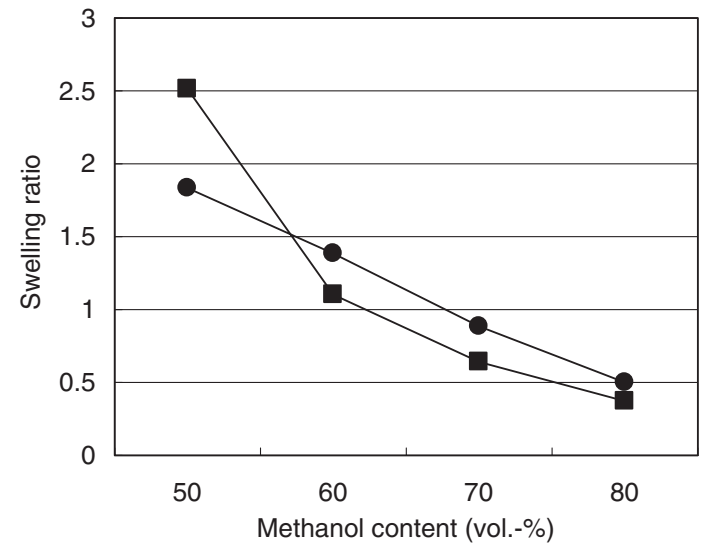

Figure 4. Swelling ratios for copolymer $\mathbf{A}(\boldsymbol{\square})$ and copolymer $\mathbf{B}$

guest molecules are physically blocked. This view was further supported by the observation that the solvent dependency in the PMC binding for copolymer $\mathbf{B}$ was much smaller than that for copolymer A. Upon changing methanol content from 50 to 80 vol.- $\%$, the binding ability of copolymer $\mathbf{A}$ is significantly reduced by nearly $90 \%$ (Figure 3(a), closed squares), whereas that for copolymer $\mathbf{B}$ is only reduced by $60 \%$ (Figure 3(b), closed circles). Since copolymer $\mathbf{B}$ has a smaller polyacrylamide content (see Table I), it is likely that the thickness of the barrier is not enough for preventing the diffusion of PMC. One should note that the binding ability of copolymer $\mathbf{B}$ is larger than that of copolymer $\mathbf{A}$ because of difference in the PEI content in the copolymers.

We then tested whether the copolymer gels are able to physically confine guest molecules within the matrices. After binding $\mathrm{PMC}$ in a mixed solvent (methanol content $=50$ vol.-\%), the copolymer gel was transferred to a mixed solvent not containing PMC. The amount of PMC that was nonspecifically taken up in the copolymer gels were negligibly small since the copolymers absorb only small portion of the solution (less than $0.25 \%$ ). After being equilibrated for $12 \mathrm{~h},{ }^{35}$ $\mathrm{HCl}$ was added to make the acid concentration of $1 \mathrm{mM}$ and then the solution was stirred for $12 \mathrm{~h}$. After that, PMC concentration in the solution was quantified to access the amount of released PMC from the copolymer gel. The results are given in Figure 5. In the case where the methanol content was 60 vol.- $\%$, PMC was nearly completely released from copolymer A. When the methanol content was 70 vol.- $\%$, it still released most of bound PMC ( $c a$. 80\%). The amount of released PMC then abruptly decreased to only $20 \%$ when the methanol content was raised to 80 vol.- $\%$. As already mentioned, the interaction between the copolymer and PMC is disrupted by the addition of $\mathrm{HCl}$. Since the solutions for the 


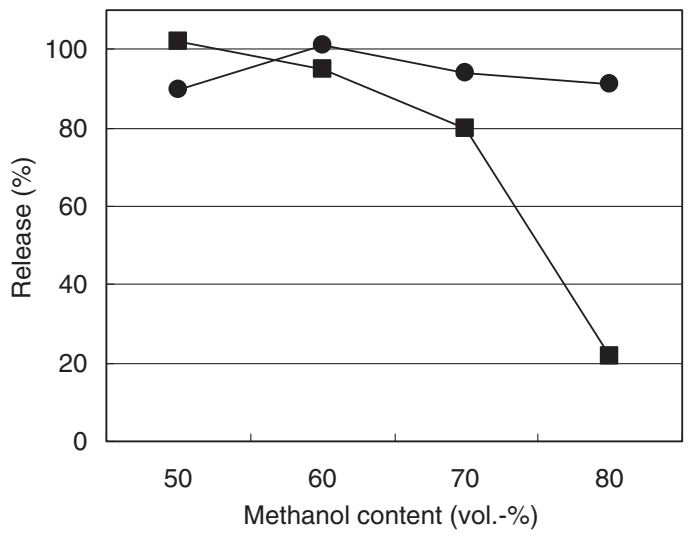

Figure 5. Percentages of PMC released from copolymer $\mathbf{A}(\boldsymbol{\square})$ and copolymer B (O).

releasing experiments contained $1 \mathrm{mM}$ of $\mathrm{HCl}, \mathrm{PMC}$ should be quantitatively released if there is no physical barrier. Therefore, the suppression of the PMC release proved that the shrunken polyacrylamide chains act as a barrier by which PMC is physically confined in the copolymer matrix. It is surprising to observe such a drastic change in the confinement ability by slightly altering the solvent composition. In contrast to the case of copolymer A, copolymer $\mathbf{B}$ showed almost no confinement ability for PMC. It is speculated that the barrier in copolymer $\mathbf{B}$ is not thick enough and has many defects through which PMC can escape. These results clearly indicate the crucial role of the thickness of the barrier for the physical confinement of guest molecules.

\section{CONCLUSION}

We have developed a novel hydrogels showing stimuliresponsive guest binding and releasing behaviors. The mass transfer within the hydrogel matrix depends on the swelling degree of the polyacrylamide chains, so that the binding and releasing characteristics can reversibly be controlled by changing solvent composition. We are now trying to utilize various kinds of functional monomers in order to introduce a variety of stimuli-responsive functions. This may ultimately lead to useful systems for, e.g., intelligent delivery systems for fertilizers, pesticide, etc.

Acknowledgment. This research was supported by Grant-inAid for JSPS Fellows from the Ministry of Education, Culture, Sports, Science and Technology of Japan. We thank Prof. Rainer Haag for supplying polyethyleneimine.

Received: January 22, 2008 Accepted: April 16, 2008 Published: June 18, 2008

\section{REFERENCES}

1. J. M. J. Fréchet, Science, 263, 1710 (1994).

2. M. Fischer and F. Vögtle, Angew. Chem., Int. Ed., 38, 884 (1999).

3. A. W. Bosman, H. M. Janssen, and E. W. Meijer, Chem. Rev., 99, 1665 (1999).

4. U. Boas and P. M. H. Heegaard, Chem. Soc. Rev., 33, 43 (2004).

5. M. H. Kleinman, J. H. Flory, D. A. Tomalia, and N. J. Turro, J. Phys. Chem. B, 104, 11472 (2000).

6. G. Pistolis, A. Malliaris, D. Tsiourvas, and C. M. Paleos, Chem. Eur. J., 5, 1440 (1999).

7. Z. Sideratou, D. Tsiourvas, and C. M. Paleos, Langmuir, 16, 1766 (2000).

8. M. Arkas, D. Tsiourvas, and C. M. Paleos, Chem. Mater., 15, 2844 (2003).

9. C. M. Paleos, D. Tsiourvas, Z. Sideratou, and L. Tziveleka, Biomacromolecules, 5, 524 (2004).

10. H. Miyake, K. Yoshida, H. Sugimoto, and H. Tsukube, J. Am. Chem. Soc., 126, 6524 (2004).

11. H. Sugimoto, R. Tajima, T. Sakurai, H. Ohmi, S. Ito, and H. Tsukube, Angew. Chem., Int. Ed., 45, 3520 (2006).

12. T. Michinobu, S. Shinoda, T. Nakanishi, J. P. Hill, K. Fujii, T. N. Player, H. Tsukube, and K. Ariga, J. Am. Chem. Soc., 128, 14478 (2006).

13. H. Tsukube, Y. Suzuki, D. Paul, Y. Kataoka, and S. Shinoda, Chem. Commun., 2533 (2007)

14. J. F. G. A. Jansen, E. M. M. de Brabander-van den Berg, and E. W. Meijer, Science, 266, 1226 (1994).

15. J. F. G. A. Jansen, R. A. J. Janssen, E. M. M. de Brabander-van den Berg, and E. W. Meijer, Adv. Mater., 7, 561 (1995).

16. J. F. G. A. Jansen and W. Meijer, Macromol. Symp., 102, 27 (1996).

17. J. F. G. A. Jansen and W. Meijer, J. Am. Chem. Soc., 117, 4417 (1995).

18. G. Yang, M. Jikei, and M. Kakimoto, Macromolecules, 32, 2215 (1999).

19. M. Jikei and M. Kakimoto, Prog. Polym. Sci., 26, 1233 (2001).

20. H. Kudo, A. Morita, and T. Nishikubo, Polym. J., 35, 88 (2003).

21. A. Morita, H. Kudo, and T. Nishikubo, J. Polym. Sci., Part A: Polym. Chem., 42, 3739 (2004).

22. A. Morita, H. Kudo, and T. Nishikubo, Polym. J., 36, 413 (2004).

23. A. Sunder, R. Hanselmann, H. Frey, and R. Mülhaupt, Macromolecules, 32, 4240 (1999).

24. R. Haag, J.-F. Stumbé, A. Sunder, H. Frey, and A. Hebel, Macromolecules, 33, 8158 (2000).

25. M. Krämer, J.-F. Stumbé, H. Türk, S. Krause, A. Komp, L. Delineau, S. Prokhorova, H. Kautz, and R. Haag, Angew. Chem., Int. Ed., 31, 4252 (2002).

26. S.-E. Stiriba, H. Kautz, and H. Frey, J. Am. Chem. Soc., 124, 9698 (2002).

27. Y. Chen, Z. Shen, L. Pastpr-Pérez, H. Frey, and S.-E. Stiriba, Macromolecules, 38, 227 (2005).

28. S.-E. Stiriba, H. Frey, and R. Haag, Angew. Chem., Int. Ed., 41, 1329 (2002).

29. A. Brownlie, I. F. Uchegbu, and A. G. Schätzlein, Int. J. Pharm., 274, 41 (2004).

30. R. Haag and F. Vögtle, Angew. Chem., Int. Ed., 43, 272 (2004).

31. R. Haag, Angew. Chem., Int. Ed., 43, 278 (2004).

32. For copolymer $\mathbf{A}, 3 \mathrm{~mL}$ of $\mathrm{H}_{2} \mathrm{O}$ and $2 \mathrm{~mL}$ of DMSO were used; for copolymer $\mathbf{B}, 1 \mathrm{~mL}$ of $\mathrm{H}_{2} \mathrm{O}$ was used.

33. The maximum binding capacities were not determined in this study.

34. In this case, stimulus is the change in the solvent composition.

35. We confirmed that PMC was scarcely released before adding $\mathrm{HCl}$. 